\section{Medicinal and herbal plants}

Publishers seem to be producing an army of books on the power of plants -how to grow them and use their products. Here are two more popular texts for those inclined to do-it-yourself medication or those interested in the subject from a more academic angle.

Guide to Medicinal Plants by P. Schauenberg and F. Paris (Lutterworth: Guildford, UK, $1977 ; £ 5.95$ ) is translated from the French and is a straightforward, workman-like production. It is responsible in its attitude towards a subject which is not always treated with the respect it deserves: there may be a thin line between therapeutic and poisonous doses in some medicines of plant origin.

The plants are arranged according to their active principles-alkaloids, flavonoids, saponosides, tannins, and so oneach chapter being prefaced by a short

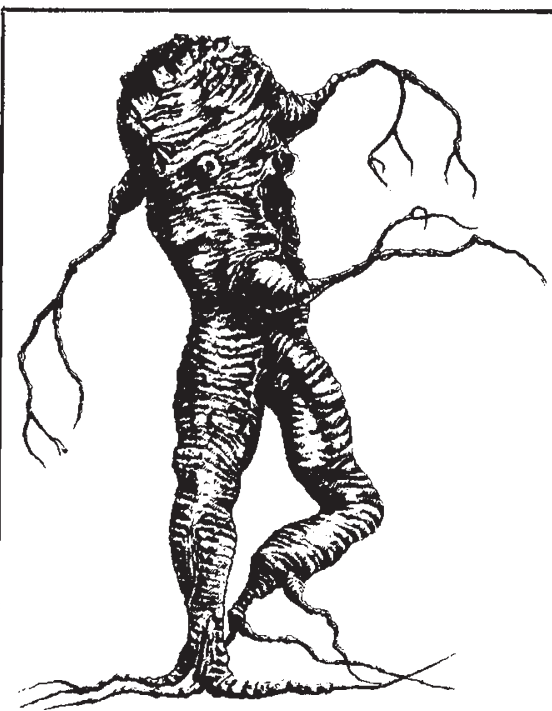

Illustration of Bryonia dioica (root), taken from A History of Herbal Plants, reviewed on this page. In the fifteenth and sixteenth centuries, the roots of the Briony were roughly shaped to represent the human form and implanted with Millet sprouts, to simulate the hairy Mandrake. These were then sold for large sums of money because of their reputed medicinal powers.

account of the constituents under consideration. Most of the plants listed are either native to or commonly cultivated in Europe, and at the end of the book there is a chapter on medicinal plants from other continents. This latter seems to be a fairly arbitrary selection, varying from coffee and sarsparilla to nux-vomica. The entry for each plant is short but adequate, giving Latin, French, German and English names, distribution, a short description, flowering and collecting seasons, active constituents, properties, and so on. A chapter on tisanes and

compresses makes fascinating reading: a gargle based on sage and red wine might make a sore throat almost worthwhile.

The occasional line drawings scattered through the text are not very helpful and could well have been omitted, but the coloured drawings at the end, though not outstanding, are pleasant and the plants recognisable.

$A$ History of Herbal Plants by R. Le Strange (Angus and Robertson: Lewes, UK, $1977 ; £ 8)$ is in complete contrast. The author has obviously read widely, if somewhat indiscriminately, and has, it seems, put down as much about each plant as his publisher would allow. Unfortunately, not all the information is accurate, and the nomenclature, both Latin and English, leaves something to be

\section{Making use of twigs}

Plants with a Purpose. By Richard Mabey Pp. 176. (Collins: London, 1977.) $£ 4.50$.

RichaRd MABEY wants us to recapture the sense of intimacy with plants that was known to our ancestors, and to help us he has written a book about the household uses of some of the commoner wild plants of Europe and North America. The result is a hybrid between a historical survey and a collection of helpful hints, which at first glance might seem appropriately subtitled $A$ Hundred and One Things to do with Twigs.

The versatile twig and its close relatives, the stick and the sprig, certainly feature prominently, and it is possible to imagine a culture based on their use. In the dark ages, before science and technology began, the twig people would rise early from their heather mattresses, and chew on twigs to clean their teeth. They used bundles of birchwood to light their fires, on which they cooked a mess of pottage prepared using whisks made from handfuls of birch twigs--very satisfying to use, though rather fiddlesome to wash, Mabey assures us. They swept

\section{Victorian \\ Natural History}

The Family Naturalist. By Michael Chinnery. Pp. 192 (Macdonald and Jane's: London, 1977.) £6.95.

I WAS fortunate enough to have a mother who was born in 1873, when Queen Victoria was on the throne, and who was one of the earliest women students of biology at what was then the Durham College of Science in Newcastle upon Tyne. Marriage prevented her from exercising her pro- desired-the Oregon grape has been known as Mahonia aquifolium for very many years now-but this no doubt is due to inadequate sources of reference.

Each entry is illustrated but the drawings are often rather odd and in a number of styles; some, such as that of Viola tricolor, resemble those in Victorian gardening books and are charming, but some of the others are formalised to the extent of looking like decorative tiles, as in the Aristolochia clematitis. A History of Herbal Plants is, however, quite entertaining.

Rosemary Angel

Rosemary Angel is Head of the Museums Department at the Royal Botanic Gardens, Kew, UK.

their floors with birch brooms and strewed them with pine twigs. Each day would include an expedition to the forest to collect twigs. Older twig people took their ash walking sticks, and everybody wore sprigs of elder or wormwood in their hats to keep flies at bay. The day's collection of woody material was carried home in wicker baskets woven from willow twigs. When a woodland fire was encountered, it was beaten out using a bunch of fine birch twigs-presumably larger than those used for the whisks. The twig children usually played with catapults made from small forked sticks.

It seems unlikely that this book will stimulate a renaissance of the twig culture, or start a mass vogue for rushlighting, nut polishes or homemade herb shampoos. Doubtless, the Forestry Commission would not be overjoyed if it did. But a pot pourri or a pressedleaf bookmark is a simple reminder of the versatility of plants. Richard Mabey's book includes many such reminders, and will encourage a greater appreciation of the value of plants. Perhaps it will even help to restore their former intimacy.

Mary Lindley

Mary Lindley is Assistant Editor of Nature and a former student of botany.

fession, but she introduced me to Natural History. From the age of three, we collected wild flowers, probably illegally, in the untidier parts of the Pollock Estate in suburban Glasgow. When, at the age of seven, I moved to rural Renfrewshire, I could already identify many of the common plants and insects. I pressed flowers and reared caterpillars in the nursery, and scared the maids with newts which escaped and found their way into the kitchen. We had all the texts for the well-brought up child. I remember particularly Eyes and No Eyes; this and other books of the same genre deserve to be reprinted. 